\title{
Seismic Performance Evaluation of Stone Masonry Houses Constructed with Reinforced Concrete Bands
}

\author{
Anju Maharjan ${ }^{l}$ and Hari Ram Parajuli ${ }^{2 *}$ \\ ${ }^{1}$ Department of Civil Engineering, Thapathali Campus, Institute of Engineering, \\ Tribhuvan University, Nepal \\ ${ }^{2}$ Executive Committee, National Reconstruction Authority, Kathmandu, Nepal \\ *Corresponding Author \\ hariparajuli@ioe.edu.np
}

\begin{abstract}
The research work was aimed evaluatingthe newly built stone masonry houses with mud mortar and with the provision of horizontal reinforced concrete (R.C.) bands. Two recently built stone masonry houses of different geometry were selected, modeled, and analyzed to investigate the seismic performance of stone masonry houses constructed with horizontal bands. Linear time history analysis was used and performance of the selected buildings was checked with the help of various numerical models. The top roof displacement, maximum drift ratio, base shear, and shell stress were compared between two selected models using three earthquake time histories. The fragility curves were also developed to identify the probability of the failure of the buildings at different peak acceleration values using three earthquake time histories.
\end{abstract}

\section{Keywords}

Stone-masonry houses, reinforced concrete bands, linear time history analysis, seismic performance

\section{Introduction}

Masonry is the most important construction material in the history of humankind. Masonry is used in various forms such as stone, clay brick, cellular concrete block, and adobe for building structures. Stone-masonry is a traditional form of construction in the regions where the sand is locally available. It represents an affordable and cost-effective housing construction. But stone masonry structures are found to be more vulnerable to earthquakes (www.nset.org.np). Past earthquakes have revealed that the stone masonry structures are susceptible to earthquake shaking. Earthquake-induced human and economic losses are unacceptably high in areas where stone masonry has been used for housing construction (Bothara and Brzev 2012).

The seismic vulnerability of these buildings is due to their heavyweight and, in most cases, how the walls have been built. Both new and existing stone masonry buildings are at risk in earthquake-prone areas of the world (Bothara and Brzev 2012). The heavyweight of the buildings without considering any engineering practices leads to a grander scale of damage. Most of the stone masonry structures were poorly constructed without following the design guidelines, while minor or no structural damages were observed in well-constructed masonry building. Poor quality of mortar is the main reason for the low tensile strength of rubble stone masonry. Timber floors and roof structures are usually not massive and therefore do not induce large seismic forces. However, typical timber floor structures are made of timber joists that are not adequately connected to structural walls. These structures are somewhat flexible and are not sufficiently attached to structural walls (Lutman 2011). The reasons for the collapse of these kinds of constructions are the lack of adequate connections between the exterior and interior walls, the poor connections between walls and slabs, the weak bond between mortar and stone in masonry walls, and the lack of building integrity. Connecting ties to the walls, such as lintel and sill bands, are usually not provided; thus, the buildings lack the integrity required to resist seismic loadings.

Many stone masonry houses are now being constructed after Gorkha Earthquake (7.8 magnitudes in $25^{\text {th }}$ April 2015) in Nepal with improved seismic resistance methods of 
construction enhancing the building integrity by tying the walls together, providing vertical reinforcement in the corner of the wall, ring beams (reinforced concrete or timber bands) at different levels in all walls of the building for tying walls together and enhancing box action. Hence, seismic performance of newly constructed stone masonry houses is required for the preservation of stone masonry houses in the future against severe earthquake damages and to flow the knowledge that stone masonry with mud mortar can also be built seismic-resistant by correct methods of construction.

\section{Methodology}

The various literature related to the works was surveyed and reviewed. In this regard, the literature concerned with the correct methods of construction of masonry buildings, properties of a masonry building, modeling strategy for the unreinforced masonry building, and reinforced

masonry buildings had been reviewed.

The place "Chautara Municipality" was selected to visit for the selection of stone masonry houses. The length, breadth, and height of selected houses, position of openings, reinforcement concrete bands, vertical reinforcement, etc. were noted. Some of the inbuilt stone masonry houses were captured in the mobile phone; the photos are incorporated as below.

The collected data were referred to prepare the plans, elevations, and sections of the two selected houses. The complete drawing was developed in the software Auto CAD which was moreover applied in modeling the houses in the Finite

\section{Element Method.}

The data obtained from the test carried out by the other researcher were used to model the stone masonry houses. Similarly, different papers published by various researchers were studied, and some of the properties that were carried out

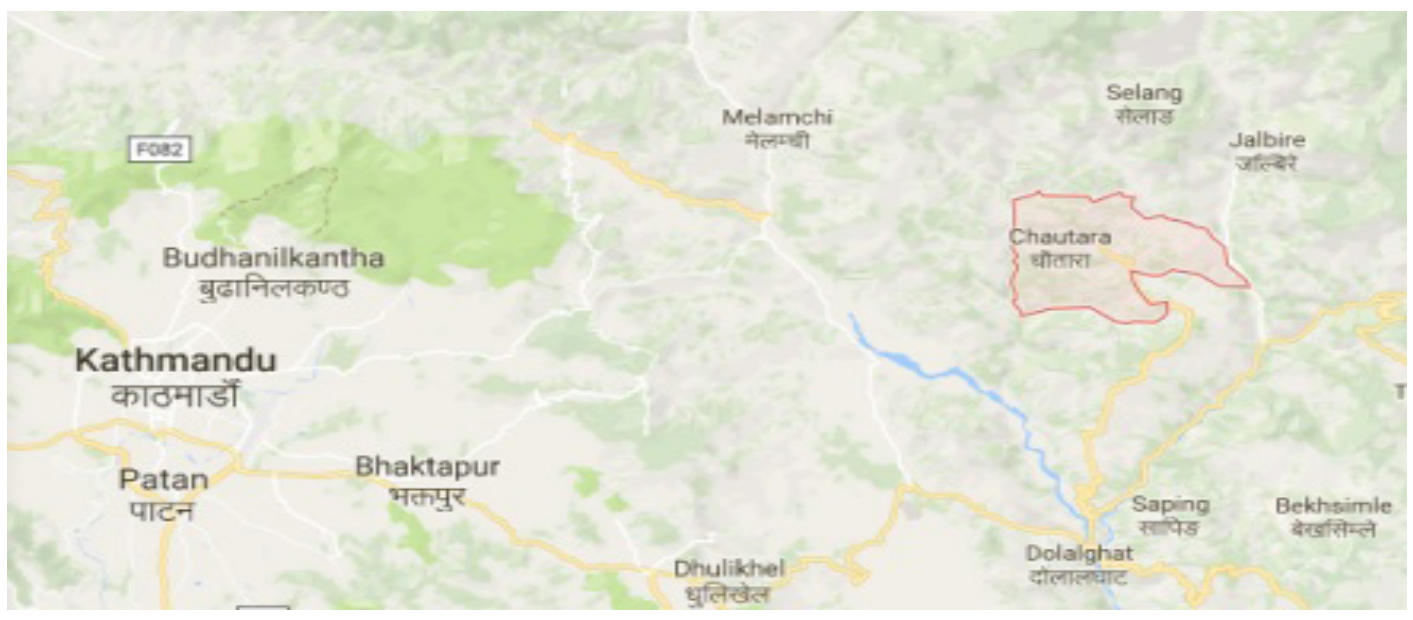

Fig: 1. Location of Chautara Municipality (Google Map)

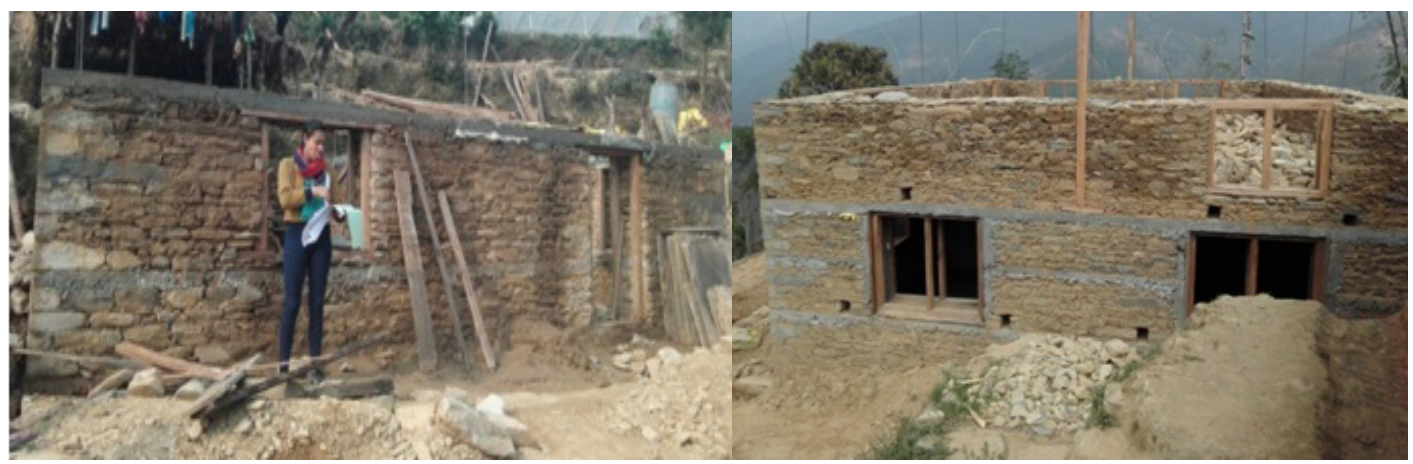

Fig: 2. Stone masonry houses in the field (Photos: Captured in Mobile) 


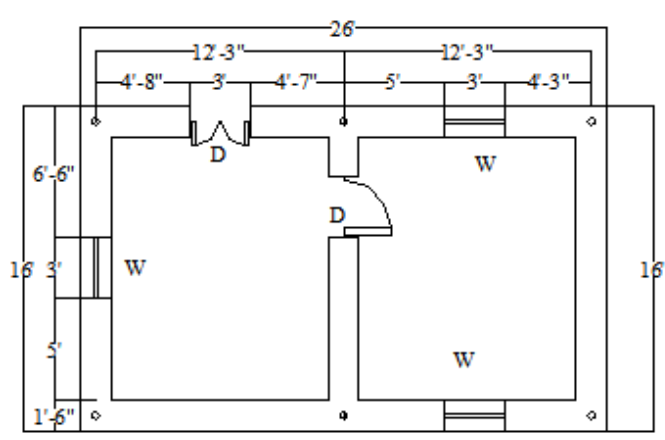

Plan of Model-1

by them had also been considered for the research work. The material properties were applied the same to both selected stone masonry houses. The materials properties were taken from experimental tests done by the researcher and various papers published by the researchers. Properties applied while modeling selected stone masonry houses were

i) Young's modulus of elasticity of wall $(E)=200$ $\mathrm{N} / \mathrm{mm}^{2}$.

ii) Unit weight of random rubble stone masonry wall $(\gamma)=17$ K.N. $/ \mathrm{m}^{3}$ Unit weight of Timber element $(\gamma)=4.47 \mathrm{KN} / \mathrm{m}^{3}$

iii) Modulus of Elasticity of Timber element $=810000 \mathrm{~K} \mathrm{~N} / \mathrm{m}^{2}$

(E)
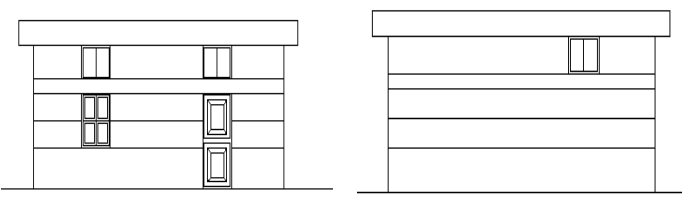

North Elevation

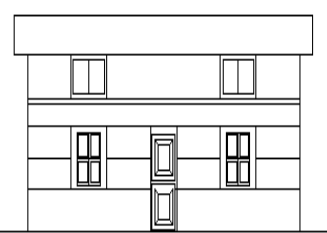

North Elevation

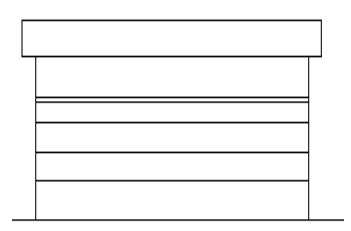

South Elevation

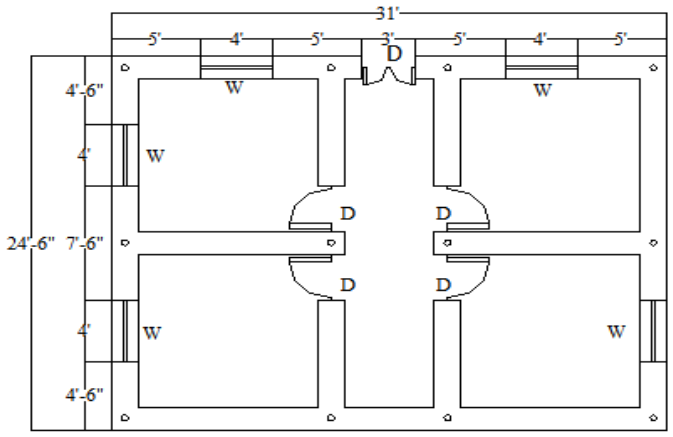

Plan of Model-2

iv) Poison's ratio of Timber element $(v)==0.3$

(Parajuli, 2016)

v) Poison's ratio of a wall $(v)=0.2$

vi) Unit weight of mud $(\gamma)=14.10 \mathrm{~K} . \mathrm{N} / \mathrm{m} 3$

(IS:875( Part 1))

In this research, the Macro-modeling technique was used; the different components of the structures were modeled as shell and area elements, whereas timber members of the structure were modeled as frame elements using SAP 2000 version 19. Three different three-time history data were used to analyze selected two stone masonry houses to evaluate the seismic performance of stone
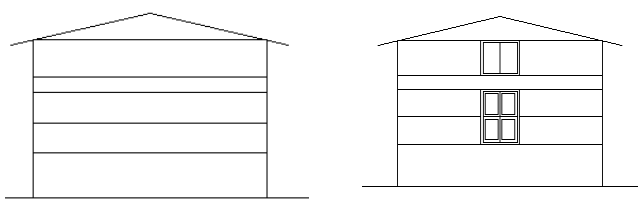

East Elevation

West Elevation

Elevations of Model-1

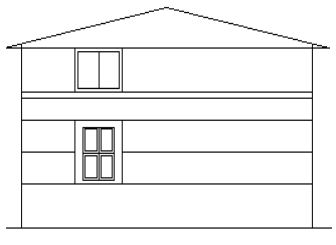

East Elevation

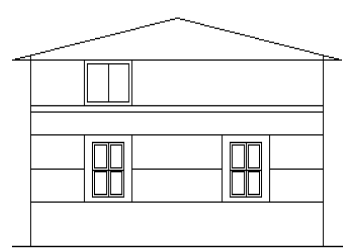

West Elevation

Elevations of Model-2

Fig: 3 Plans and Elevations of Model-1 and Model-2 
masonry houses constructed with Reinforced concrete bands.

\section{Modeling of Masonry Building}

Two stone masonry houses constructed with R.C. bands were selected for the analysis, which was under construction in the Chautara Village. The stone masonry wall has been built with stone with mud mortar, was modeled in shell and area. Two typical houses of one story plus attic floor and twostory stone masonry houses with wall thickness 18 " were shaped by SAP 2000 version 19. The rectangle shell element was considered for the model of the wall. The partition walls were also considered during the modeling of the selected stone masonry houses. The base of the model is made fixed since the houses were constructed with the provision of a vertical reinforcement bar and plinth band. Bands with three-inch (3") thickness were modeled as a frame element. Vertical bars were modeled as a frame element and designed section with solid sections whose diameter is $12 \mathrm{~mm}$. The opening frames, rafter, battens, ridge, joists, timber beam, roof post, etc. were modeled as frame elements and designed sections with solid sections. The dimensions regarding all frame elements were considered from the NBC codes 203 and 204. The floor system consists of wooden joists over which the wooden planks were laid. The flooring was of mud under timber planks supported on timber joists (Bothara and Brzev, 2011).

For modeling the timber floor, a three-dimensional linear beam element was used to model the timber joist and timber beam. The connection of the timber floor/roof with the masonry wall was assumed that it was simply resting on the wall because the timber nails or iron ties, if present, were heavily deteriorated or damaged over the long years. So, simply supported connection was used for modeling the joint between the timber joist and masonry wall. Similarly, the battens were also simply supported with the rafter with moment release. The model was analyzed by the Seismic Coefficient method, in which the seismic effect, a horizontal force, was considered the percentage of the total weight of the building. In this method, dynamic forces, which act on the structure during the excitation, were converted into equivalent horizontal force (Khadka, 2013). In this research work, the seismic coefficient method was used as described by the NBC code.

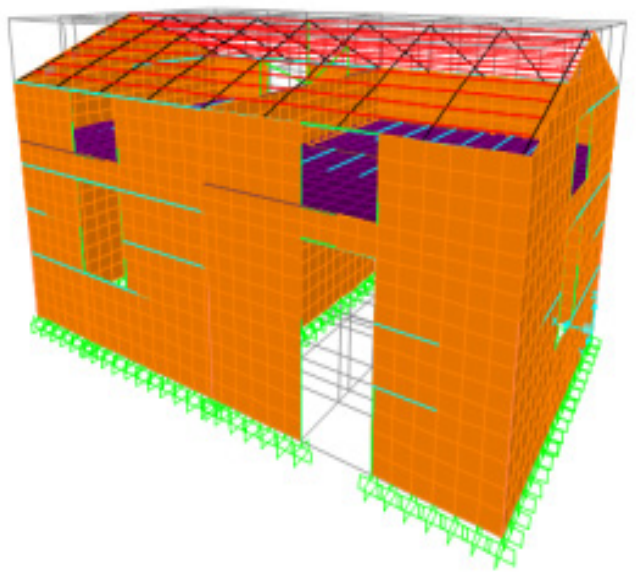

Model-1

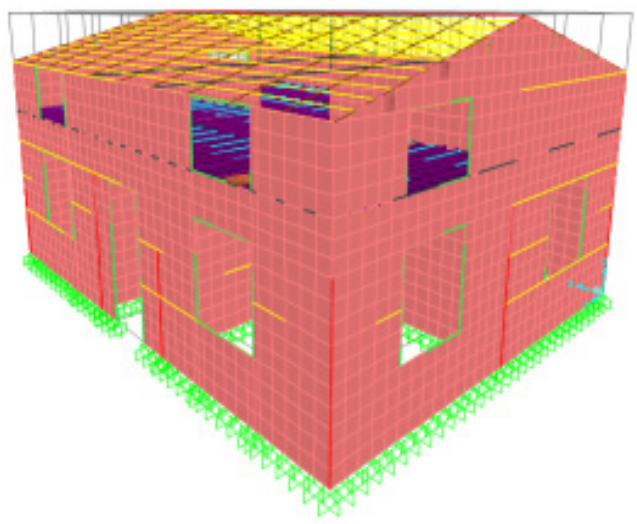

Model-2

Fig: 4 Random rubble mud bonded Stone Masonry Houses (SAP 2000 version 19)

Battens and rafters at the roof level have been taken into considerations. Covering above the batten was not taken into considerations since covering material only transfers the load to battens. The roof load depends on what type of roofing is used. Approximate calculations suggest a roof load equal to $1.5 \mathrm{~K} \mathrm{~N} / \mathrm{m}^{2}$ which represents a thin slate roof, corrugated galvanized iron (CGI) sheets, or thick rammed earth (Parajuli 2016). The load coming from the roof battens are distributed on the top of the masonry walls. The gravity load was calculated based on the unit weight of the material, and the live load was taken as 2.5 $\mathrm{K} \mathrm{N} / \mathrm{m}^{2}$. Similarly, the dimensions of other frame 
elements as per NBC codes 202, $203 \& 204$ were taken as

\section{Table 1. Dimensions of the Frame element}

\begin{tabular}{cll}
\hline S.N. & Frame & Section \\
\hline 1 & Bands & $3^{\prime *} 18^{\prime \prime}$ \\
2 & Joist & $100 \mathrm{~mm} * 75 \mathrm{~mm}$ \\
3 & Rafter & $2.5^{\prime \prime} 4^{\prime \prime}$ \\
4 & Batten & $1.5^{\prime *} 2^{\prime \prime}$ \\
5 & Roof Post & $240 \mathrm{~mm}^{*} 120 \mathrm{~mm}$ \\
6 & Ridge & $3^{\prime *} .^{\prime \prime}$ \\
7 & Opening Frame & $100 \mathrm{~mm} * 75 \mathrm{~mm}$ \\
8 & Vertical Rein- & $12 \mathrm{~mm}$ diameter \\
& forcement & \\
\hline
\end{tabular}

\section{Analysis}

The model was first completed in Sap 2000 version 19 . The selected houses were analyzed by the Seismic Coefficient Method, where the design horizontal seismic force coefficient was calculated as per NBC 105 code. The three earthquake time history records were selected for the analysis, i.e., Loma Gilroy 2 earthquake (0.36 g), El Centro earthquake (0.29 g), and Gorkha earthquake $(0.16 \mathrm{~g})$. Ground motion parameters may be acceleration, velocity, or displacement. The actual ground acceleration records were considered the records of similar events at the instrument station. Peak ground acceleration was used to rescale actual time history to a higher and lower level of shaking. The maximum PGA values of history data are found out, and the data of that time history is divided by maximum PGA value to rescale to $1 \mathrm{~g}$. The others are rescaled, giving a scale factor of 0.95 on the data rescale to $1 \mathrm{~g}$ to rescale to
$0.95 \mathrm{~g}$ and so on. Each time history data was rescaled to get PGAs of $0.05 \mathrm{~g}, 0.15 \mathrm{~g}, 0.25 \mathrm{~g}$, $0.35 \mathrm{~g}, 0.45 \mathrm{~g}, 0.55 \mathrm{~g}, 0.65 \mathrm{~g}, 0.75 \mathrm{~g}, 0.85 \mathrm{~g}$, $0.95 \mathrm{~g}$ and $1.0 \mathrm{~g}$. Since the different three-time history data were used for the analysis, and these historical data were of different PGA values. These data were rescaled to the same PGA values so that the fair comparison can be made. Since the earthquake time histories have different characteristics, such as period, the amplitude at various time intervals, etc., the results are obtained with different values. From linear time history analysis, base shear, shell stress, and displacement and drift ratio at different storey were graphically represented for different rescaled PGA.

\section{Results And Discussions}

SAP 2000 version 19 was preferred for the modeling of the representative stone masonry houses. Linear time history analysis was applied to evaluate the seismic performance of the stone masonry houses constructed with reinforced concrete bands. The Gorkha earthquake, Loma Gilroy 2 earthquake, and El Centro earthquake data were used during the analysis.

Fig: 6, Fig: 7, and Fig: 8 show storey displacement $(\mathrm{mm})$ and storey drift ratio (\%) curve for the building (Model-1) at different PGA (g) of three different earthquake time history. The storey displacement curve shows displacement goes on increasing with the storey height at particular PGA (g). Similarly, storey drift ratio (\%) curve shows the maximum drift ratio on the second floor. For different earthquake data for Model-2 building, the same pattern of the curve is obtained and is presented in Fig: 9, Fig: 10, and Fig: 11. Likewise, Fig:12show Top displacement curve, Base shear
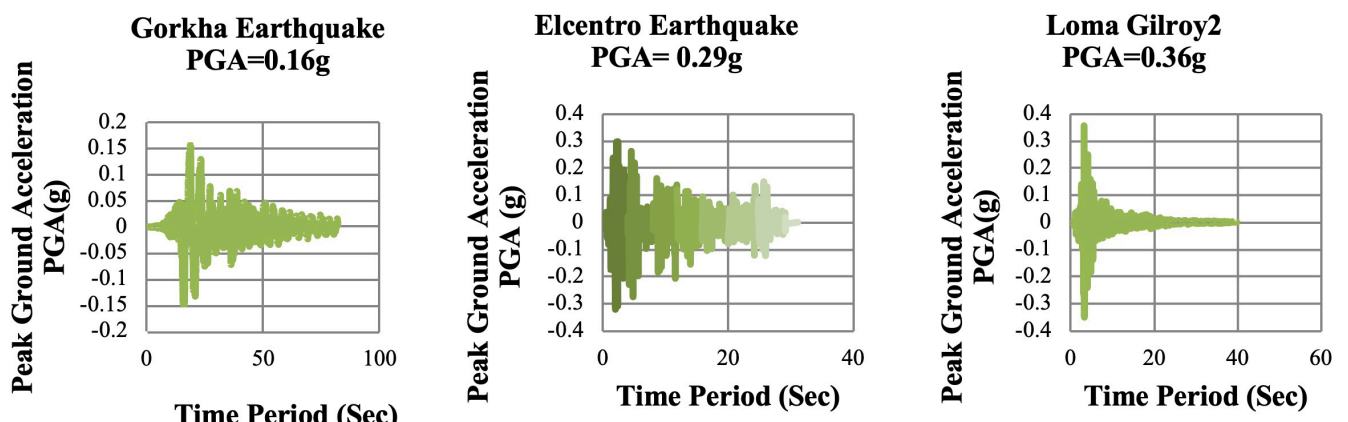

Fig. 5. Earthquake time history, (KantipathStation, Deep soil Software, Inbuilt) 
curve, and Shell stress curve of building Model-1 for different earthquake time history. The curve is linear, which shows Top displacement increases with increase PGA (g).

Similarly, the Base shear curve and Shell stress also vary linearly with increase PGA $(\mathrm{g})$. Since linear time history analysis has shown that all the parameters along with Sa /g vary linearly, and as expected, the curve is linear. For Model-2 similar curve is obtained and is presented in Fig: 13.

Analytical fragility curves are drawn in Fig: 14 and Fig:15 for the Model-1 and Model-2, respectively. The fragility curves for various levels of damage state for each type of house are shown in Fig: 14 and Fig:15. From these curves, it is obtained that the probability of failure of the selected buildings (Model-1 and Model-2) decreases with the increase in value of standard deviation ( $\beta \mathrm{ds}$ ) value in two-time history (El Centro and Loma Gilroy 2) cases. But for Gorkha Earthquake, the probability of failure of building Model-1 and Model-2 is increase with the increase in the value of standard deviation ( $\beta \mathrm{ds}$ ) value. For the Gorkha Earthquake, the probability of failure of building Model-1for PGA $1.0 \mathrm{~g}$ is around $10 \%, 20 \%$, and $30 \%$ with the value of $\beta \mathrm{ds}=0.3,0.45,0.65$, respectively. Similarly, For Gorkha Earthquake, the probability of failure of building Model-2 for PGA $1.0 \mathrm{~g}$ is around $2 \%, 9 \%$, and $18 \%$ with the value of $\beta \mathrm{ds}=$ $0.3,0.45,0.65$ respectively.

The probability of failure is meager percent in the analysis of houses applying the Gorkha Earthquake than the other two earthquake histories. Hence, the performance of stone masonry houses constructed with reinforced concrete bands can standby against the type of earthquake nature like "Gorkha Earthquake" with less damage.

i)The response of Model -1 due to three different earthquake time histories

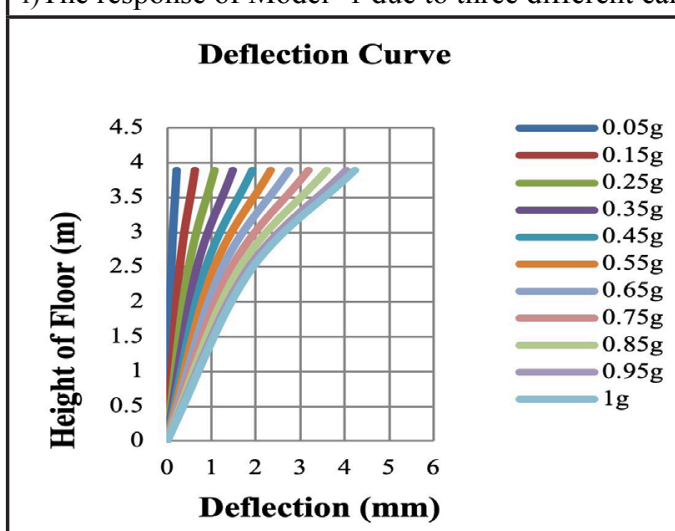

Drift Ratio Curve

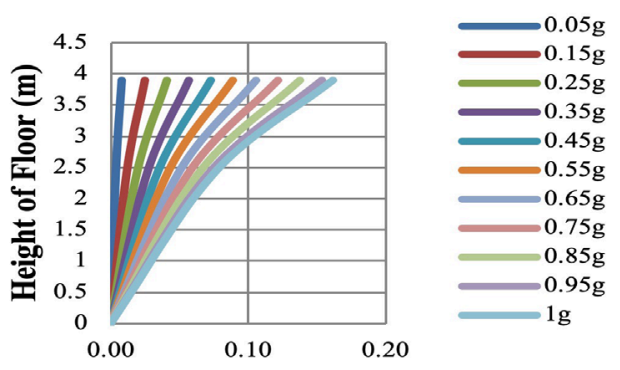

Drift Ratio (\%)

Fig. 6. Deflection Curve and Drift Ratio Curve at Different PGA (g)

[Gorkha Earthquake]

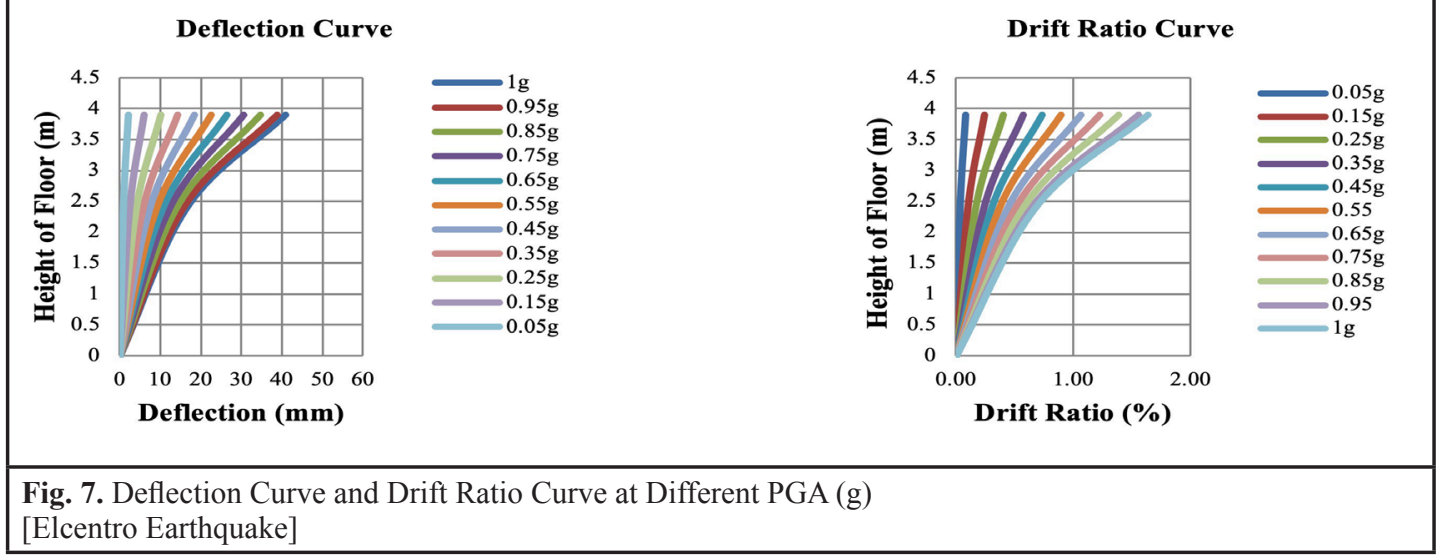




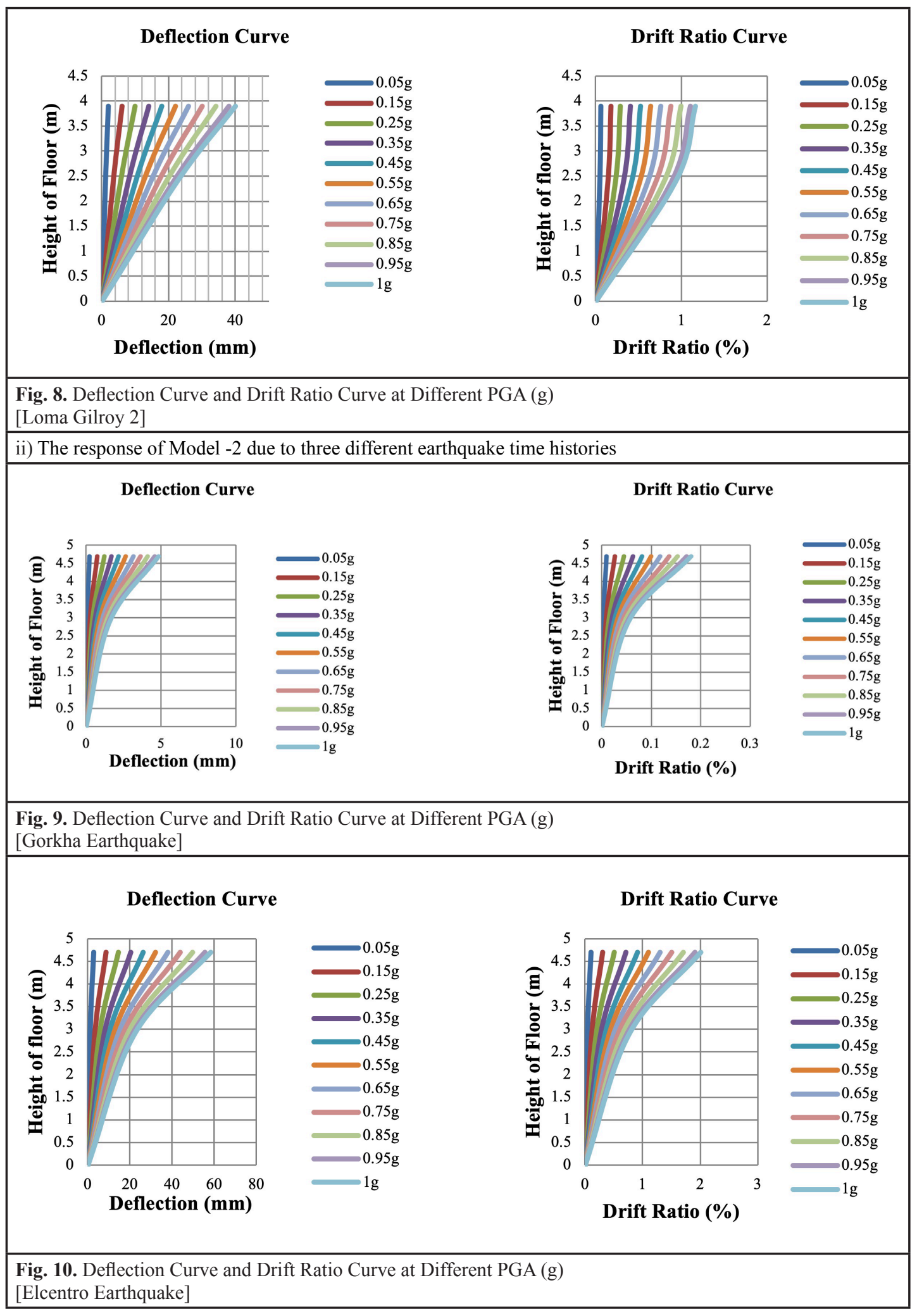




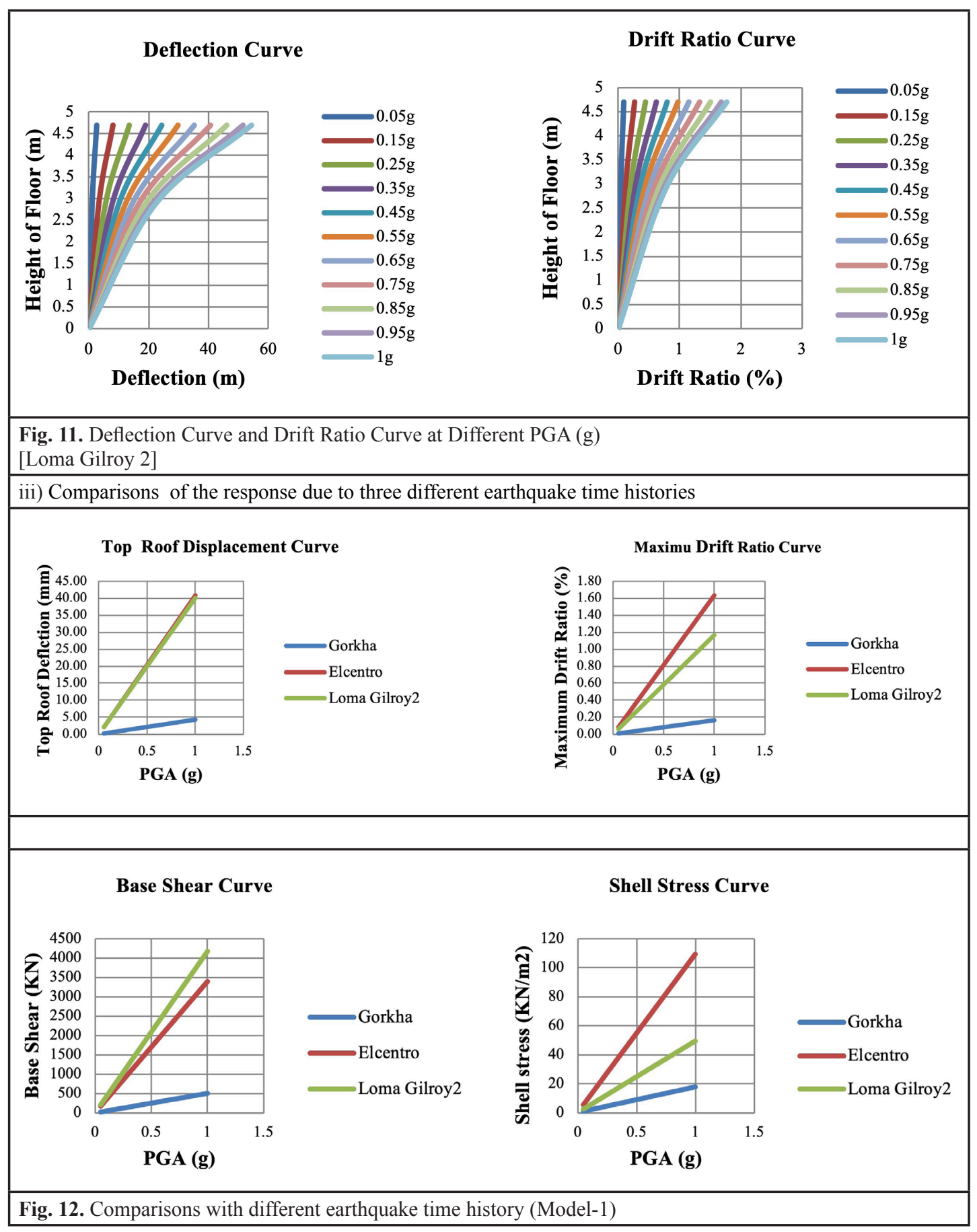




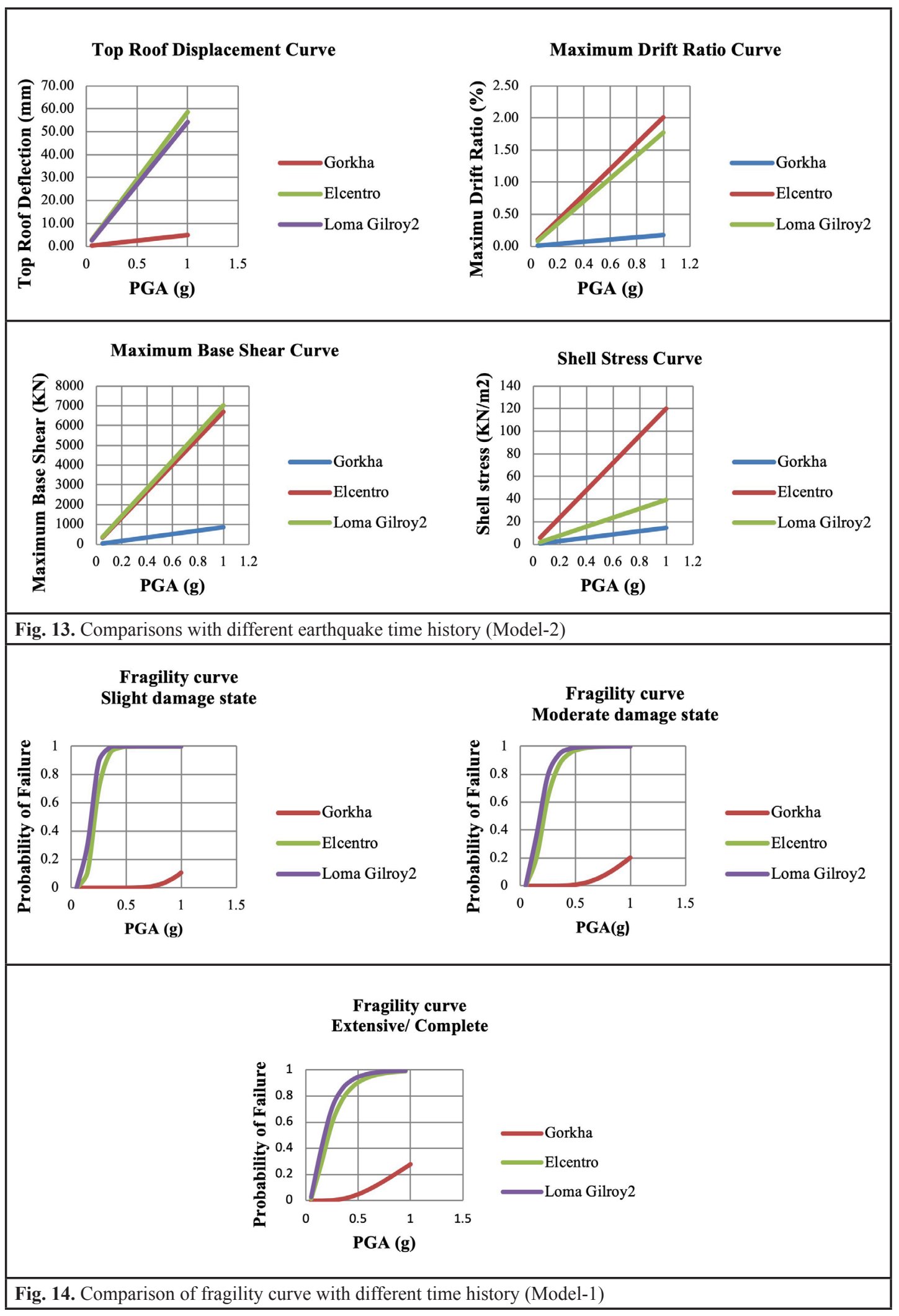




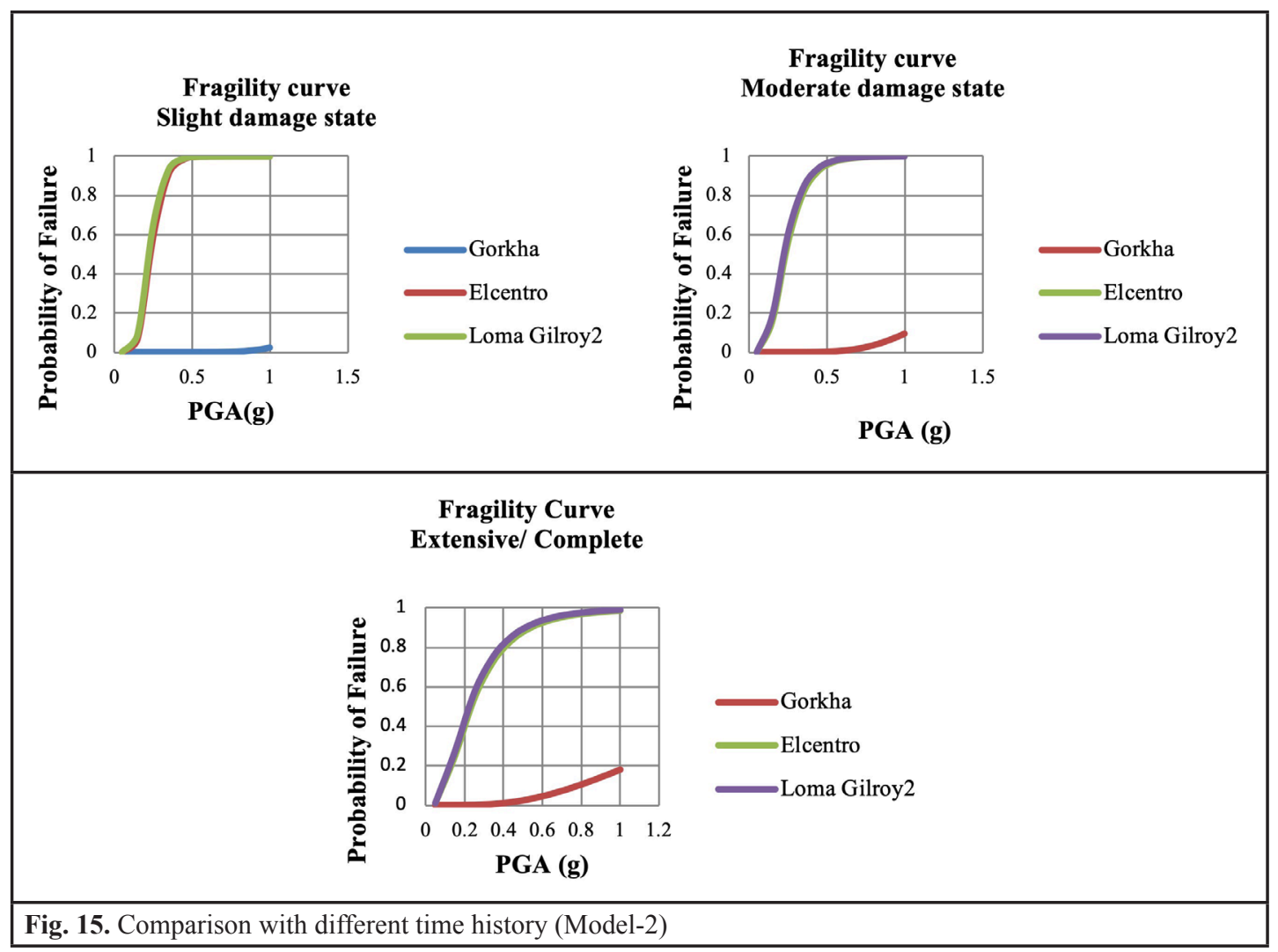

\section{Conclusions}

Two typical types of stone masonry houses are modeled as thin shell element and timber joist, timber batten, and timber rafter as well as wooden beams as frame element as equivalent beam hinged at wall support by using SAP version 19 . Earthquake loading is given in the form of ground motion histories with varying levels of peak ground acceleration. The response of the selected stone masonry houses to different earthquake time histories is found in terms of top displacement, drift ratio, base shear, and shell stress.

The fragility curves for different earthquakes, considering three levels of damage state, are obtained. These fragility curves can be used to find out the probability of failure of the building for different earthquakes at different PGA. These curves are useful for evaluating the seismic vulnerability of the existing buildings and estimating the necessary measures to strengthen the existing building. The obtained fragility curves show that the probability of failure of both
Model-1 and Mode-2 during the analysis with the Gorkha Earthquake time history is very low compare to the other two-time account.

\section{References}

Can C. SIMSIR, Mark A. ASCHHEIM and Daniel P. ABRAMS. Out-Of-Plane Dynamic Response of Unreinforced Masonry Bearing Walls Attached To Flexible Diaphragms. $13^{\text {th }}$ World Conference on Earthquake Engineering, Vancouver, B.C, Canada, 2004

Correction/Exception Manual for Masonry Structure for Houses That Have been Built Under the Housing Reconstruction Programme, Government of Nepal, National Reconstruction Authority, 2017

Design Catalogue for Reconstruction of Earthquake Resistant Houses. Volume I. 2015

Hari Ram Parajuli, Performance Evaluation of Mud Bonded Stone Masonry Houses under Earthquake Loadings, Nepal journal of science and technology (Nepal J Sci-Tech), 
2016

Jacob Alex Kollerathu, S. Krishnachandran \& Arun Menon. Modeling and Seismic Analysis of existing masonry structures, Department of civil engineering, India Institute of Technology Madras, India, 2016

Jitendra Bothara, Svetlana Brzev, A TUTORIAL: Improving the Seismic Performance of Stone Masonry Buildings, Earthquake Engineering Research Institute, Oakland, California, 2011

Jitendra Bothara, Beca Carter Hollings \&Ferner Limited, Wellington, New Zealand, and Svetlana Brzev, British Columbia Institute of Technology, Burnaby, BC, Canada, A Tutorial on Improving the Seismic Performance of Stone Masonry Dwellings: A Compendium of Worldwide Experience, 2012

Marjana Lutman, Stone Masonry Construction, Slovenian National Building and Civil Engineering Institute, Slovenia, 2011
M. Monteiro, R. Bento, Seismic Characterization and Evaluation of an Old Masonry Building, ICIST, Instituto Superior Técnico, Technical University of Lisbon, Portugal, 2013

Ricardo León Bonett / Alex Barbat / Lluis Pujades / Sergio Lagomarsino / Andrea Penna, Performance assessment for unreinforced masonry buildings in low seismic hazard areas, Revista de Ingenierías Universidad de Medellín Universidad de Medellin, COLOMBIA, 2006

S.E. Chidiac, Seismic guidelines for stonemasonry components and structures, McMaster University, Hamilton, Ontario, Canada, 2002.

Shyam Sundar Khadka, Seismic Performance of Traditional Unreinforced Masonry Building in Nepal, Department of Civil \& Geomatics Engineering, Kathmandu University, 2013 